J. Dairy Sci. 92:423-432

doi:10.3168/jds.2008-1163

(c) American Dairy Science Association, 2009.

\title{
Prediction of coagulation properties, titratable acidity, and pH of bovine milk using mid-infrared spectroscopy
}

\author{
M. De Marchi, ${ }^{\star 1}$ C. C. Fagan, $\dagger$ C. P. O’Donnell, $\dagger$ A. Cecchinato, ${ }^{\star}$ R. Dal Zotto, ${ }^{\star}$ M. Cassandro, ${ }^{\star}$ M. Penasa, ${ }^{\star}$ \\ and G. Bittante* \\ *Department of Animal Science, University of Padova, Viale dell'Università 16, 35020 Legnaro, Padova, Italy \\ †Biosystems Engineering, UCD School of Agriculture, Food Science and Veterinary Medicine, University College Dublin, Belfield, Dublin 4, Ireland
}

\section{ABSTRACT}

This study investigated the potential application of mid-infrared spectroscopy (MIR 4,000-900 $\mathrm{cm}^{-1}$ ) for the determination of milk coagulation properties (MCP), titratable acidity (TA), and $\mathrm{pH}$ in Brown Swiss milk samples $(\mathrm{n}=1,064)$. Because MCP directly influence the efficiency of the cheese-making process, there is strong industrial interest in developing a rapid method for their assessment. Currently, the determination of MCP involves time-consuming laboratory-based measurements, and it is not feasible to carry out these measurements on the large numbers of milk samples associated with milk recording programs. Mid-infrared spectroscopy is an objective and nondestructive technique providing rapid real-time analysis of food compositional and quality parameters. Analysis of milk rennet coagulation time (RCT, min), curd firmness $\left(\mathrm{a}_{30}, \mathrm{~mm}\right)$, TA $\left(\mathrm{SH}^{\circ} / 50 \mathrm{~mL} ; \mathrm{SH}^{\circ}=\right.$ Soxhlet-Henkel degree $)$, and $\mathrm{pH}$ was carried out, and MIR data were recorded over the spectral range of 4,000 to $900 \mathrm{~cm}^{-1}$. Models were developed by partial least squares regression using untreated and pretreated spectra. The MCP, TA, and $\mathrm{pH}$ prediction models were improved by using the combined spectral ranges of 1,600 to $900 \mathrm{~cm}^{-1}, 3,040$ to 1,700 $\mathrm{cm}^{-1}$, and 4,000 to $3,470 \mathrm{~cm}^{-1}$. The root mean square errors of cross-validation for the developed models were $2.36 \mathrm{~min}$ ( $\mathrm{RCT}$, range $24.9 \mathrm{~min}), 6.86 \mathrm{~mm}\left(\mathrm{a}_{30}\right.$, range $58 \mathrm{~mm}$ ), $0.25 \mathrm{SH}^{\circ} / 50 \mathrm{~mL}$ (TA, range $3.58 \mathrm{SH}^{\circ} / 50 \mathrm{~mL}$ ), and $0.07(\mathrm{pH}$, range 1.15). The most successfully predicted attributes were TA, RCT, and $\mathrm{pH}$. The model for the prediction of TA provided approximate prediction $\left(\mathrm{R}^{2}=0.66\right)$, whereas the predictive models developed for RCT and $\mathrm{pH}$ could discriminate between high and low values $\left(\mathrm{R}^{2}=0.59\right.$ to 0.62$)$. It was concluded that, although the models require further development to improve their accuracy before their application in

Received March 10, 2008.

Accepted September 11, 2008.

${ }^{1}$ Corresponding author: massimo.demarchi@unipd.it industry, MIR spectroscopy has potential application for the assessment of RCT, TA, and $\mathrm{pH}$ during routine milk analysis in the dairy industry. The implementation of such models could be a means of improving $\mathrm{MCP}$ through phenotypic-based selection programs and to amend milk payment systems to incorporate MCP into their payment criteria.

Key words: Brown Swiss milk, coagulation properties, mid-infrared spectroscopy, chemometrics

\section{INTRODUCTION}

Cheese yield is influenced by coagulation properties of milk (MCP), which can vary greatly from cow to cow, with 30 to $40 \%$ of this variation explained by genetic differences (Ikonen et al., 2004; Cassandro et al., 2008). Improvement of MCP will facilitate the optimization of cheese moisture, yield, and quality (O'Callaghan et al., 2000). Selection of milk for cheesemaking on the basis of its MCP would greatly assist the cheese maker in obtaining greater and more consistent cheese yields. Several studies have demonstrated that genetic improvement of MCP could be employed to improve cheese yield (Ikonen, 2000); in fact, a few MCP measurements per cow per lactation would be sufficient for a reliable genetic evaluation (Ikonen et al., 1999; Bittante et al., 2002; Cassandro et al., 2008).

O'Callaghan et al. (2002) reviewed several systems (optical, thermal, mechanical, and vibrational) for monitoring milk coagulation during cheesemaking. However, all the methods reviewed have limitations for use in large-scale MCP determination. The measurements are time-consuming and hence, direct assessment of MCP for all cows involved in milk recording programs is not feasible. Skilled personnel are also required to carry out these techniques. One such technique for the assessment of MCP is the computerized renneting meter (Polo Trade, Monselice, Italy), which is based on the drag force technique (Ikonen et al., 2004; Cassandro et al., 2008; De Marchi et al., 2008). It can determine the rennet coagulation time (RCT, min) and curd firmness $\left(\mathbf{a}_{\mathbf{3 0}}, \mathbf{m m}\right)$ of up to 10 samples concurrently. 
Several factors influence milk coagulation kinetics including the nature and concentration of the coagulation enzyme, temperature, acidity, and calcium and protein concentrations of the milk (O'Callaghan et al., 2001). Titratable acidity (TA) plays a fundamental role in all phases of milk coagulation. This includes the aggregation rate of para-casein micelles and the reactivity of rennet. Titratable acidity also influences the rate of syneresis and determines the suitability of milk for cheese making. In the production of premium cheeses, milk with low acidity (hypoacid milk) is generally considered unsuitable for cheesemaking because of its negative effects on the rheology of the acid-rennet curd and on the textural properties of the cheese paste (Formaggioni et al., 2001). The $\mathrm{pH}$ of milk affects both the enzymatic and aggregations reactions; that is, lowering the $\mathrm{pH}$ decreases the colloidal stability of milk.

Mid-infrared (MIR) spectroscopy involves the measurement of the intensity of the absorption by a sample at wavelengths in the spectral range of 4,000 to 200 $\mathrm{cm}^{-1}$. The wavelength at which absorption occurs is characteristic of specific types of chemical bonds. Midinfrared spectroscopy is widely employed in routine quality control applications. It has been applied to the measurement of milk protein content (Etzion et al., 2004) and composition (Lynch et al., 2006), and prediction of cheese texture (Fagan et al., 2007).

Although MIR spectroscopy has been applied for the determination of several milk properties (e.g., milk composition), no studies are available in literature investigating its use for the combined prediction of $\mathrm{MCP}$ and milk acidity. Karoui et al. (2006) predicted the
$\mathrm{pH}$ and other Emmental cheese properties using MIR spectroscopy, whereas Al-Qadiri et al. (2008) predicted the $\mathrm{pH}$ of pasteurized skim milk using short wavelength near-infrared spectroscopy.

The development of a technology for the rapid and simultaneous measurement of milk could facilitate the assessment of all milk properties (protein, lipid, casein, somatic cell score, bacterial count, MCP, $\mathrm{pH}, \mathrm{TA}$ ) that are critical for the genetic selection of dairy cattle. To date the lack of demonstrated technologies for rapid routine determination of MCP has restricted the use of MCP measurements in the dairy industry. The objective of this study was to investigate the potential application of MIR spectroscopy to predict MCP and acidity ( $\mathrm{TA}$ and $\mathrm{pH}$ ) of individual milk Brown Swiss samples.

\section{MATERIALS AND METHODS}

\section{Sample Collection}

A total of 1,200 Brown Swiss cows reared in 37 herds located in northern Italy were sampled from June 2006 to July 2007. After initial data screening, which aimed to remove records with incomplete information, 1,064 samples were available for the study. The average number of days in milk and milk yield of the cows selected for this study were $( \pm \mathrm{SD}) 201 \mathrm{~d}( \pm 121 \mathrm{~d})$ and $28 \mathrm{~kg} / \mathrm{d}$ $( \pm 8 \mathrm{~kg} / \mathrm{d})$ respectively.

After collection, milk samples without any preservative were stored in portable refrigerators $\left(4^{\circ} \mathrm{C}\right)$ and transferred to the milk quality laboratory of the Veneto

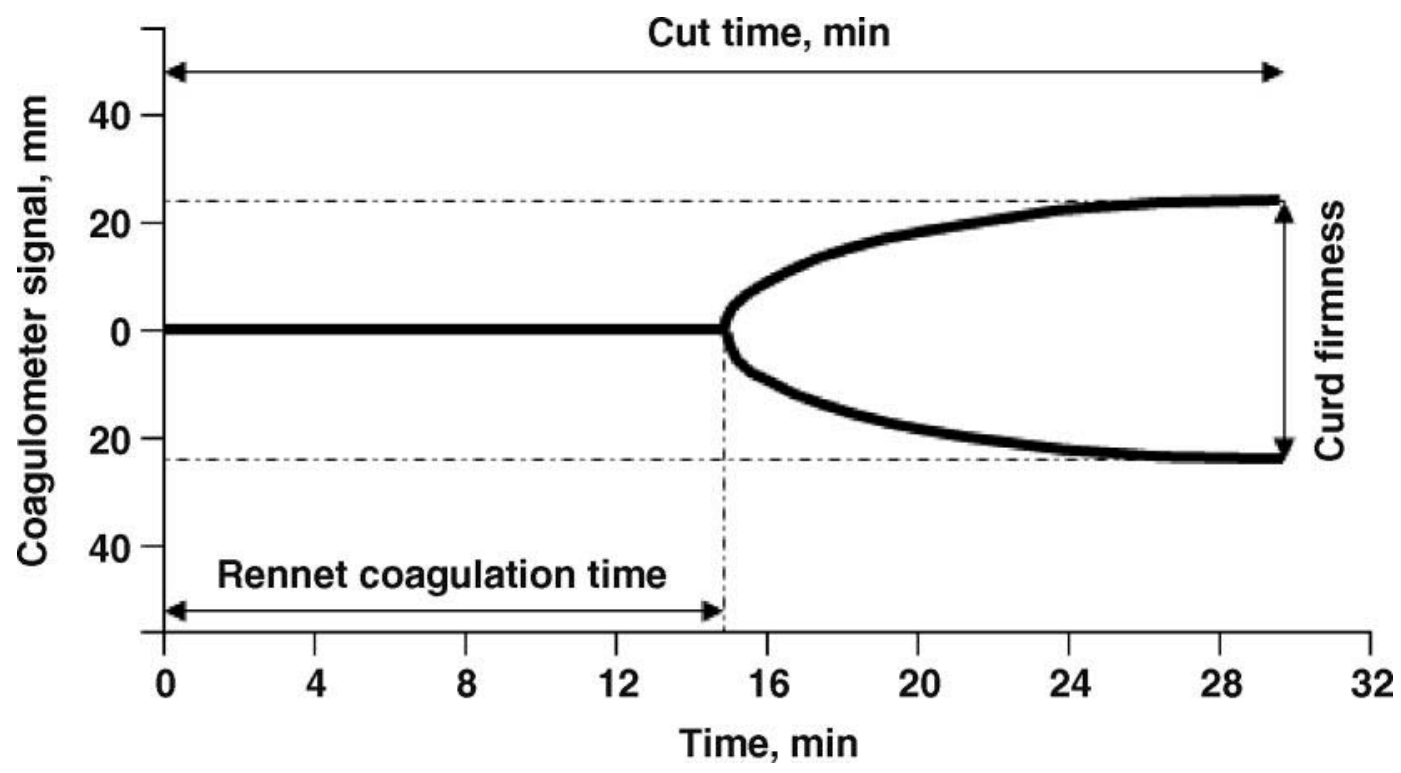

Figure 1. Data output from the milk coagulation meter showing calculated parameters: rennet coagulation time and curd firmness 30 min after addition of the clotting enzyme. 
Agricoltura Institute (Thiene, Italy). All analyses were done within $3 \mathrm{~h}$ of collection. Measurements of RCT, $\mathrm{a}_{30}$, TA, and $\mathrm{pH}$ were also carried out.

\section{Coagulation Properties}

Measurements of MCP were carried out using a computerized renneting meter (Polo Trade). Samples (10 $\mathrm{mL}$ ) were heated to $35^{\circ} \mathrm{C}$, and $200 \mu \mathrm{L}$ of rennet (Hansen standard 190 with $63 \%$ chymosin and $37 \%$ pepsin, Pacovis Amrein AG, Bern, Switzerland) diluted to 1.6\% (wt/wt) in distilled water was added to milk. Measurement of MCP ended at 31 min after the addition of the enzyme. The principle of the computerized renneting meter is based on the control of the oscillation that is driven by an electromagnetic field created by a swinging pendulum. A survey system measures differences in the electromagnetic field due to milk coagulation. During milk coagulation, a pendulum is immersed into the milk container. The greater the extent of coagulation, the smaller the pendulum swing.

This analysis provided measurements of RCT, which is the time between the addition of the clotting enzyme and the beginning of the coagulation process, and $\mathrm{a}_{30}$, measured $31 \mathrm{~min}$ after addition of the clotting enzyme (Figure 1). This method, which is considered to be a reference method for RCT and $\mathrm{a}_{30}$ determination, has been widely used to monitor the milk coagulation properties (Ikonen et al., 1999; Ikonen, 2000; Ikonen et al., 2004; Cassandro et al., 2008).

\section{Titratable Acidity and $\mathrm{pH}$}

Titratable acidity was recorded as Soxhlet-Henkel degree $\left(\mathbf{S H}^{\circ}\right)$ using a Crison Compact D meter (Crison Instruments SA, Alella, Spain) according to the method proposed by Anonymous (1963), and pH was measured with a $\mathrm{pH}$ meter (Crison Instruments SA).

\section{MIR Acquisition}

The MIR spectra were collected from $0.25-\mathrm{mL}$ samples over the spectral range of 4,000 to $900 \mathrm{~cm}^{-1}$ using a Milko-Scan FT120 Fourier transform infrared (FTIR) interferometer (Foss Electric A/S, Hillerød, Denmark). Duplicate spectra were captured for each sample and averaged before data analysis.

\section{Multivariate Data Analysis}

Principal component analysis (PCA) and partial least square (PLS) regression were performed using the Unscrambler software (v.9.6; Camo A/S, Oslo, Norway). Spectral data subjected to PCA and PLS produce a new smaller set of variables called principal components (PC) or loadings, respectively. Principal components analysis provides graphical representations of similarities and differences between spectra, and was employed to identify possible outliers in the spectral data set and to investigate sample distribution (Martens and Naes, 1989). Partial least squares regression is widely used to establish a calibration model and to provide a correlation between reference data and values predicted using MIR spectral data (Hubert and Vanden Branden, 2003; Al-Qadiri et al., 2008).

Prediction models were developed using PLS regression and confirmed using random cross-validation (number of segment $=20$ and samples per segment $=53)$. All prediction residuals were then combined to compute the root mean square error of cross-validation (RMSECV; Hubert and Vanden Branden, 2003). Models were developed using raw, normalized (N), multiplicative scatter corrected (MSC), first derivative (Savitzky-Golay, 3 data points each side), and $\mathrm{N}$ plus first derivative spectra. Several criteria were used to determine the proficiency of the predictive models;

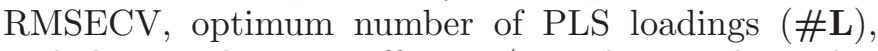
and the correlation coefficient (r; Hubert and Vanden Branden, 2003; Downey et al., 2005).

The practical utility of the calibrations were assessed using the range error ratio (RER). Values for this ratio are calculated by dividing the range of a given parameter by the RMSECV for that parameter (Williams, 1987). Although susceptible to the presence of extreme values at both ends of the range, the RER is useful for assessing the practical utility of predictive models. Models with an RER of $<3$ have little practical utility; RER values of between 3 and 10 indicate limited to good practical utility and $>10$ the model has a high utility value (Williams, 1987). In this study the preferred model was that with the lowest RMSECV value, the greatest $\mathrm{r}$ value, and the lowest \# $\mathrm{L}$.

\section{RESULTS AND DISCUSSION}

\section{Coagulation Properties, TA, and pH}

A summary of the values obtained are shown in Table 1. The table highlights the high degree of variability in $\mathrm{RCT}(\mathrm{CV}=26 \%)$ and $\mathrm{a}_{30}(\mathrm{CV}=21 \%)$ measurements, which should facilitate the development of robust models. The mean values of RCT (14.9 min) and $\mathrm{a}_{30}(41.7$ $\mathrm{mm}$ ) are close to the optimal values recommended for cheese making as proposed by Zannoni and Annibaldi (1981). The values for RCT, $\mathrm{a}_{30}$, TA, and $\mathrm{pH}$ are similar to those reported by Mariani et al. (1997) in Brown Swiss milk samples. Rennet coagulation time and $\mathrm{a}_{30}$ values reported in this study are indicative of faster 


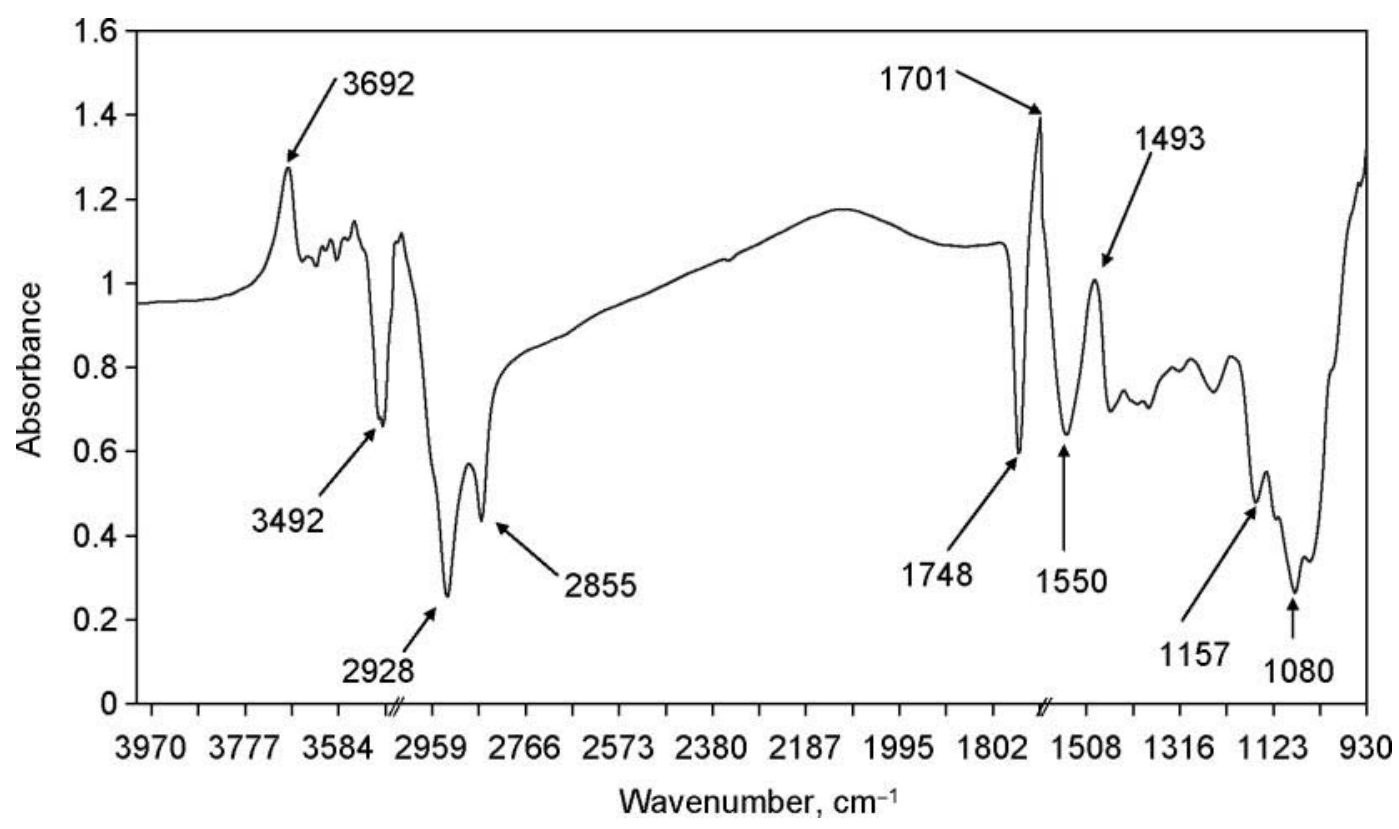

Figure 2. Example of algorithm unprocessed mid-infrared spectra for milk.

coagulation rates than those reported by Cassandro et al. (2008) for individual Holstein-Friesian milk samples (16.9 min and $32 \mathrm{~mm})$. The high variability of TA values was also similar to those reported by De Marchi et al. (2007, 2008) and Cassandro et al. (2008).

\section{MIR Spectra}

Previous research has recommended that before analysis a portion of the MIR spectra may be omitted because of its low signal-to-noise ratio (Pillonel et al., 2003). In an examination of the spectra collected in this study, 2 regions $\left(3,470\right.$ to $3,040 \mathrm{~cm}^{-1}$ and 1,700 to $1,600 \mathrm{~cm}^{-1}$ ) of the spectra were found to have high noise levels and were therefore omitted from further analysis. The high level of noise at these wavelengths may have been because of the absorption of water in the spectral regions (Hewavitharana and Brakel, 1997; Jørgensen and Næs, 2004; Fagan et al., 2007).

An example of a truncated mid-infrared spectra is shown in Figure 2. Curley et al. (1998) assigned protein to specific bands in the MIR spectra of raw milk; that is, 1,570 to $1,550 \mathrm{~cm}^{-1}$. These results were confirmed by
Etzion et al. (2004), Hewavitharana and Brakel (1997), and Luginbühl (2002). Lipids are known to contribute to the region 3,000 to $2,800 \mathrm{~cm}^{-1}$, which accounts for the observed peaks at 2,928 and $2,855 \mathrm{~cm}^{-1}$ (Lefèvre and Subirade, 2000) and between 1,736 and 1,805 $\mathrm{cm}^{-1}$, where $1,745 \mathrm{~cm}^{-1}$ is the frequency correlated with the vibration of the fatty acid carbonyl group (Coates, 2000). The peaks in the fingerprint region 640 to 1500 $\mathrm{cm}^{-1}$ are due to $\mathrm{C}-\mathrm{H}$ bending $\left(1493 \mathrm{~cm}^{-1}\right)$ and $\mathrm{C}-\mathrm{O}$ stretching $\left(1157,1080 \mathrm{~cm}^{-1}\right)$.

Principal components analysis of the untreated spectra allowed for an investigation of the influence plot and hence the identification of possible outliers. Samples were observed with high leverage and medium-to-high residual X variance values and vice versa. However, as no sample was observed with both extreme leverage and residual $\mathrm{X}$ variance values it was decided that no sample should be removed as an outlier because these samples are potentially part of the natural sample population and may provide valuable information. The score plot of PC1 and PC2, obtained from PCA, provided information regarding sample distribution (data not shown). Principal components 1 and 2 explained

Table 1. Statistical summary for rennet coagulation time (RCT), titratable acidity (TA), and pH

\begin{tabular}{lcclc}
\hline Trait & $\mathrm{n}$ & Mean & Range & $\mathrm{SD}$ \\
\hline $\mathrm{RCT}, \min$ & 1,049 & 14.96 & $4.40-29.30$ & 3.84 \\
$\mathrm{TA}, \mathrm{SH}^{\circ} / 50 \mathrm{~mL}^{1}$ & 1,063 & 3.26 & $1.19-4.77$ & 0.43 \\
$\mathrm{pH}$ & 1,064 & 6.69 & $5.88-7.03$ & 0.12 \\
\hline
\end{tabular}

${ }^{1} \mathrm{SH}^{\circ}=$ Soxhlet-Henkel degree. 
49 and $23 \%$ of the observed variation in the data, respectively. The fat content of the samples tended to increase along PC1. Samples with high protein content were located at the positive and negative extremes of PC2 and PC1, respectively, whereas the samples with low protein content were located at the negative and positive extremes of $\mathrm{PC} 2$ and $\mathrm{PC} 1$, respectively. When the loading for PC1 was examined, major peaks were observed at $1747,2855,2936$, and $3495 \mathrm{~cm}^{-1}$, which can be attributed to lipids, whereas peaks were observed at 1550,3692 , and $3036 \mathrm{~cm}^{-1}$ in the PC2 loading, which can be attributed to amides and lipids.

\section{Prediction of Coagulation Properties}

Prediction models were developed using the combined spectral ranges of 1,600 to $900 \mathrm{~cm}^{-1}, 3,040$ to 1,700 $\mathrm{cm}^{-1}$, and 4,000 to $3,470 \mathrm{~cm}^{-1}$. They were developed using spectra in several forms: untreated, N, MSC, first and second derivatives, and $\mathrm{N}$ plus each derivative step, giving 7 models for each predicted parameter. A second derivative pretreatment offered no improvement in model accuracy for any attribute; hence, those prediction results are not shown.

Table 2 presents the results of the models developed for the prediction of analyzed traits using untreated, $\mathrm{N}$, MSC, first derivative, and first derivative plus $\mathrm{N}$ spectra. The RMSECV, r, and \#L were used to compare models for accuracy. In the case where 2 or more models gave equal or similar results for a given parameter, the preferred model (shown in bold in Table 2) was the one that produced the lowest RMSECV value and the greatest $r$ value. If more than one model was produced in which these criteria were equal, then the preferred model was the one incorporating the lowest number of loadings.

Table 2 presents the results of the models developed for the prediction of coagulation properties. Although models for the prediction of $\mathrm{a}_{30}$ were developed, none were considered satisfactory $\left(\mathrm{R}^{2}=0.37\right)$ and therefore are not presented. The results show that the most accurate prediction model (lowest RMSECV value, the greatest $\mathrm{r}$ value, and the lowest \#L) for RCT was obtained using untreated spectral data. The preferred model for predicting the RCT (shown in bold in Table 2) had RMSECV values of $2.36 \mathrm{~min}$, and the corresponding RER value was 10.6. These results demonstrate that mid-infrared spectroscopy and multivariate data analysis have potential to predict RCT.

Figure 3 shows the preferred regression models for RCT (highlighted in bold in Table 2). The accuracy of each model can be evaluated using the coefficients of determination $\left(\mathrm{R}^{2}\right)$ between the predicted and measured values, as stated by Williams (2003). A value for

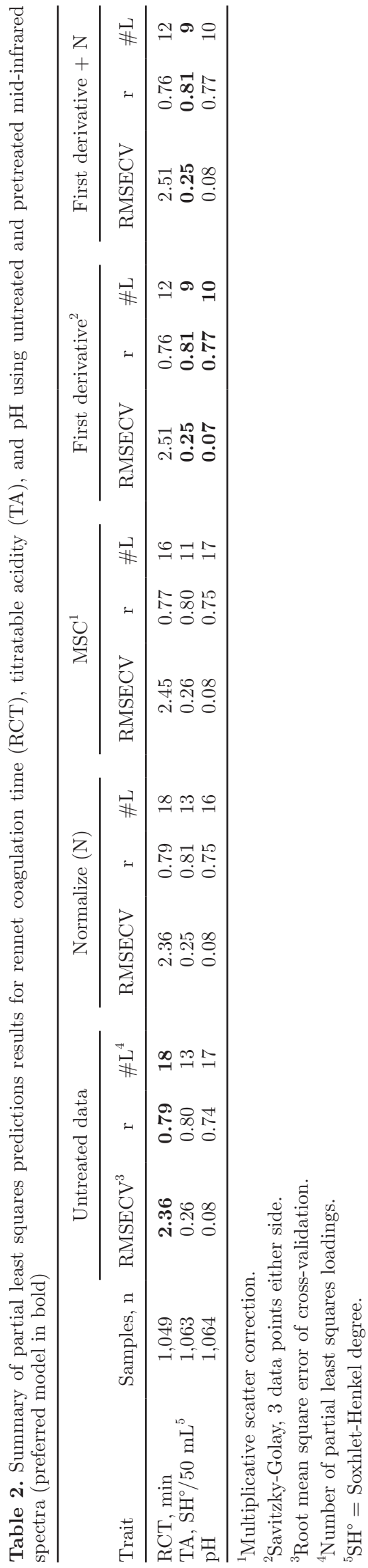

Journal of Dairy Science Vol. 92 No. 1, 2009 


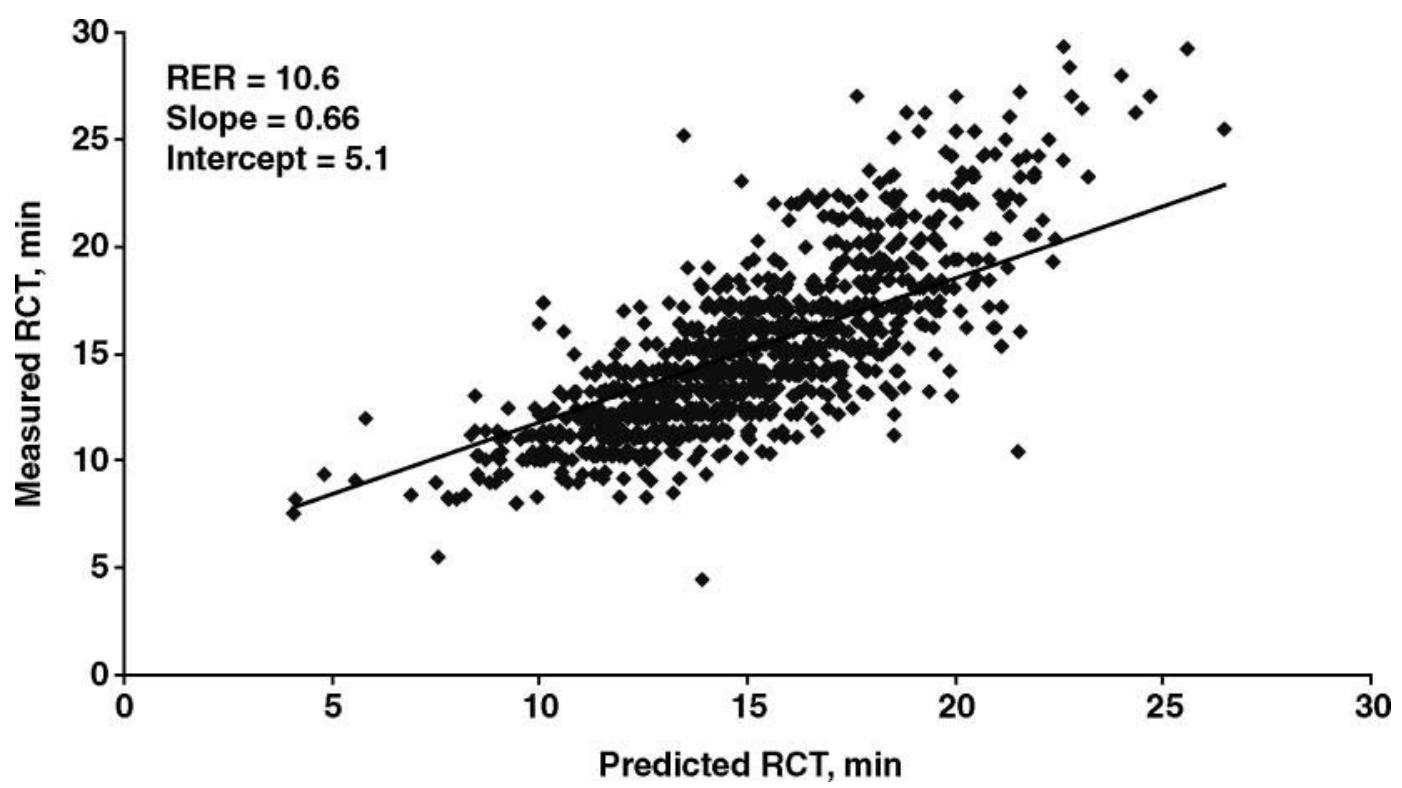

Figure 3. Linear regression plots of measured versus predicted rennet coagulation time (RCT, min) using untreated mid-infrared spectra. $\mathrm{RER}=$ range error ratio.

$\mathrm{R}^{2}$ between 0.50 and 0.65 indicates that discrimination between high and low values can be made. A value for $\mathrm{R}^{2}$ between 0.66 and 0.81 indicates approximate predictions, whereas a value for $\mathrm{R}^{2}$ between 0.82 and 0.90 reveals good predictions. Models having a value for $\mathrm{R}^{2}$ above 0.91 are considered excellent (Williams, 2003). The RCT model $\left(\mathrm{R}^{2}=0.62\right)$ allowed for discrimination between high and low RCT values. Although there is a high degree of scatter observed in Figure 3, which indicates that the current model is not sufficiently accurate to be employed in the dairy industry, the model demonstrates the potential of MIR spectroscopy for the rapid and nondestructive measurement of the $\mathrm{RCT}$ of milk, indicating that this technique warrants further investigation. The potential of MIR spectroscopy in predicting MCP has not been previously demonstrated.

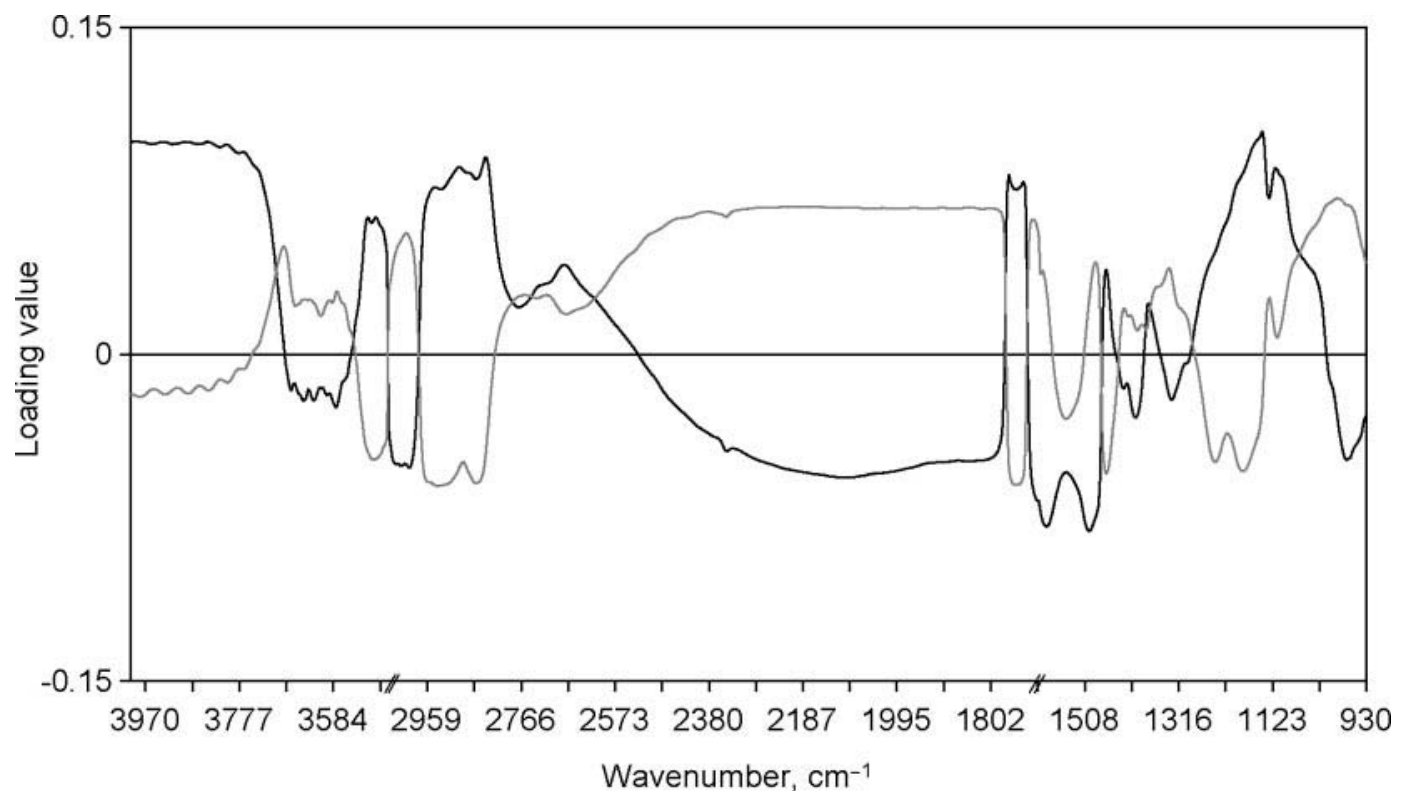

Figure 4. Plot of loadings $1(-)$ and $2(\cdots)$ for rennet coagulation time (RCT, min) using untreated mid-infrared spectra. 
a)

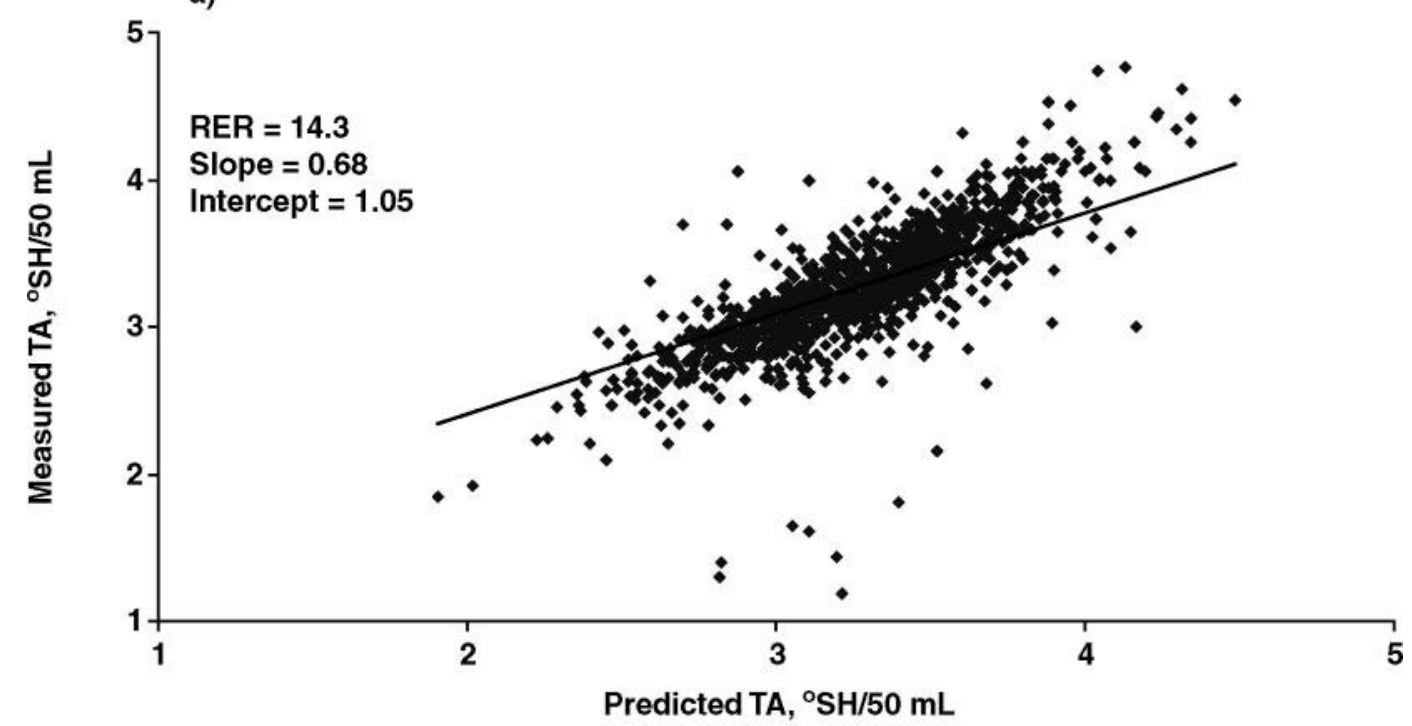

b)

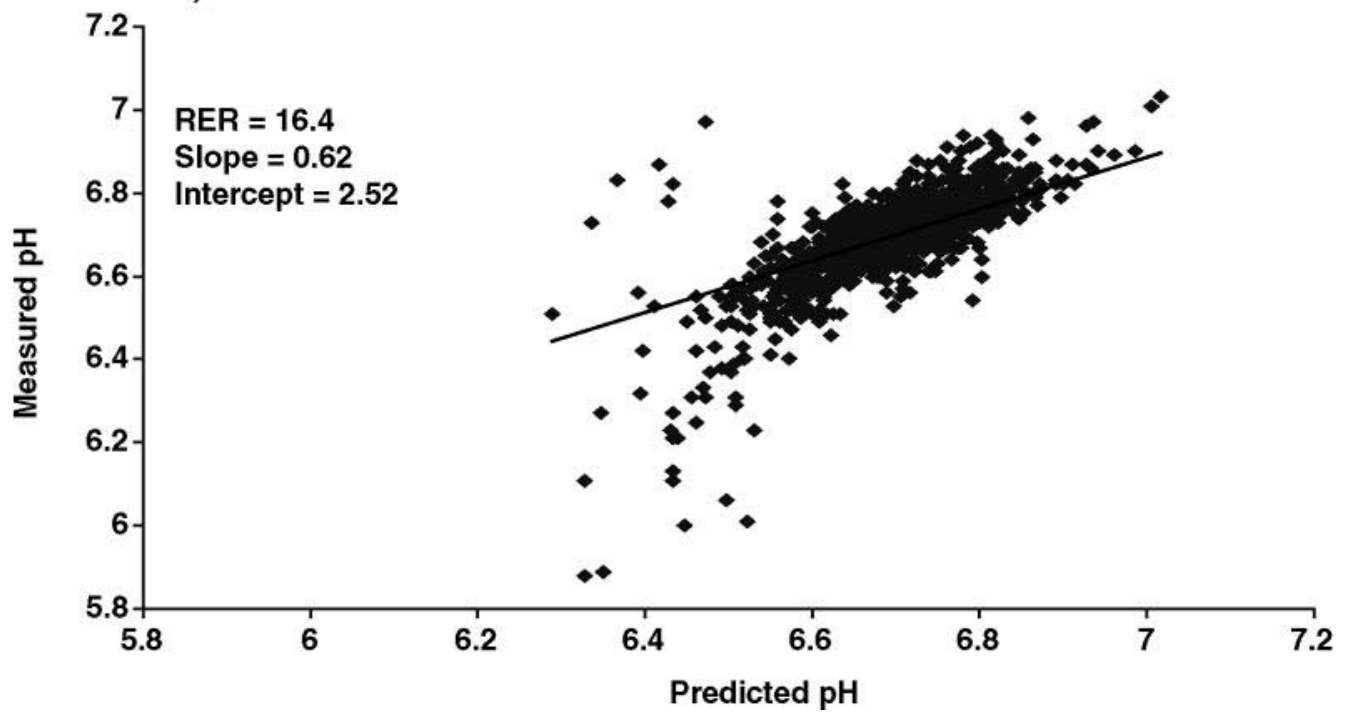

Figure 5. Linear regression plots of measured versus predicted a) titratable acidity ( $\mathrm{TA}, \mathrm{SH}^{\circ} / 50 \mathrm{~mL}$ ) and b) $\mathrm{pH}$ using pretreated (first derivative) mid-infrared spectra. $\mathrm{RER}=$ range error ratio; $\mathrm{SH}^{\circ}=$ Soxhlet-Henkel degree.

It should also be noted that the \#L incorporated into the RCT model was 16 (Table 2). This is a relatively high number of loadings and ideally, if a model were to be applied in such an application in the future, a lower number of loadings would be preferable.

To investigate a molecular basis for the prediction of MCP, the model loadings were examined. The first 2 loadings of the RCT model accounted for $55 \%$ of the variation in the spectral data and $13 \%$ of the variation in the RCT data. A plot of the first 2 loadings for the RCT model is shown in Figure 4. There was considerable structure present in the loading plots.

For the RCT model, several peaks were observed in the fingerprint region $\left(1,500-900 \mathrm{~cm}^{-1}\right)$ of the spectra.
The peaks occurring at $968,1,115,1,146$, and 1,180 $\mathrm{cm}^{-1}$ may be attributed to $\mathrm{C}-\mathrm{O}$ and $\mathrm{C}-\mathrm{C}$ stretching, respectively, whereas $\mathrm{O}-\mathrm{C}-\mathrm{H}, \mathrm{C}-\mathrm{C}-\mathrm{H}$, and $\mathrm{C}-\mathrm{O}-\mathrm{H}$ bending account for peaks at 1,466 and $1,331 \mathrm{~cm}^{-1}$, respectively. A peak was also observed at $1,240 \mathrm{~cm}^{-1}$ which may be due to amide III or phosphate bands (Hewavitharana and Brakel, 1997). Dominant peaks are also observed at 1,589 and $1,500 \mathrm{~cm}^{-1}$, which can be attributed to amide II. Peaks associated with lipids $(2,935,2,839,1,763$, $1,751 \mathrm{~cm}^{-1}$ ) were also apparent in loadings 1 and 2 of the RCT model (Figure 4a).

These results can be explained by the effect of milk protein and fat content on milk coagulation. Bastian et al. (1991) found the protein level had a small effect on 


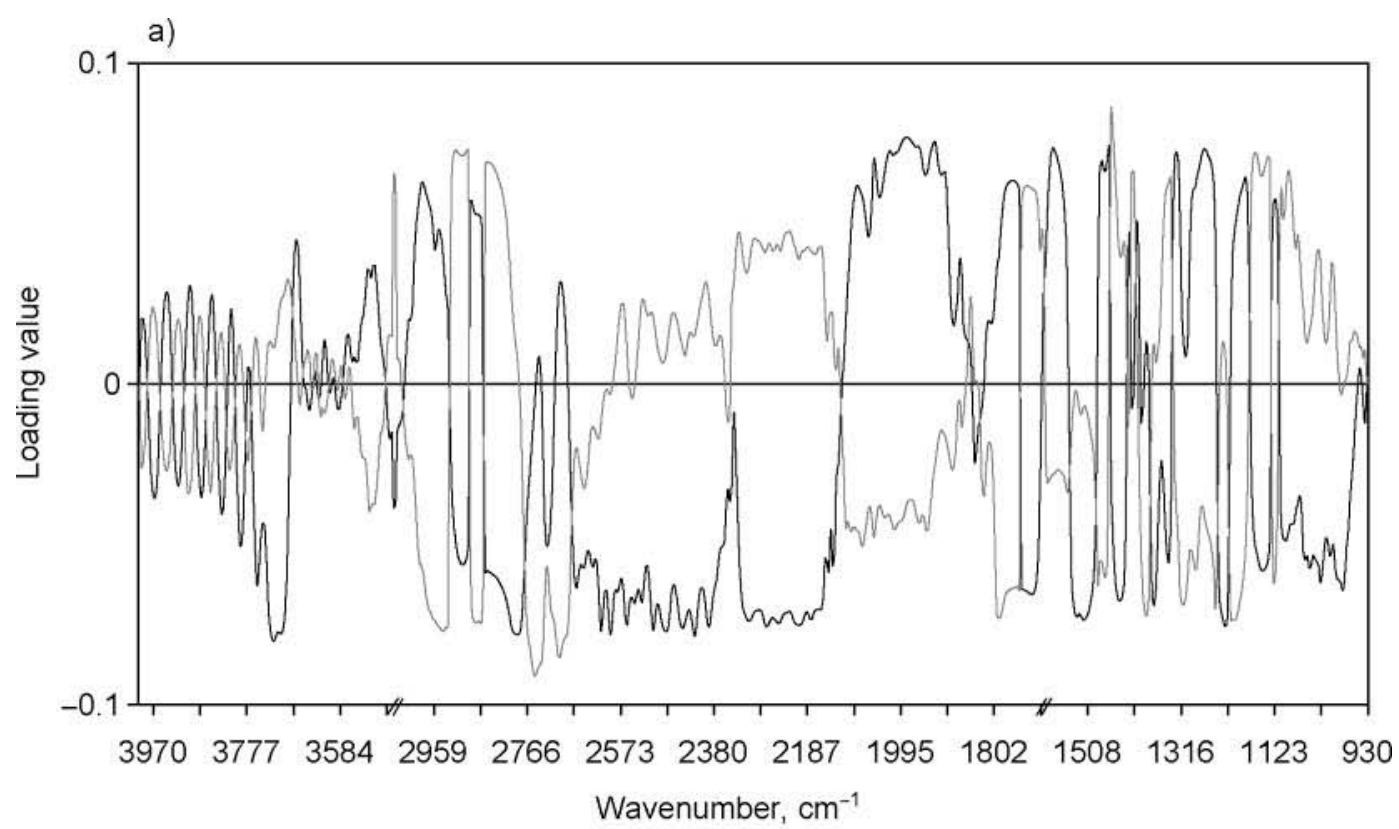

b)

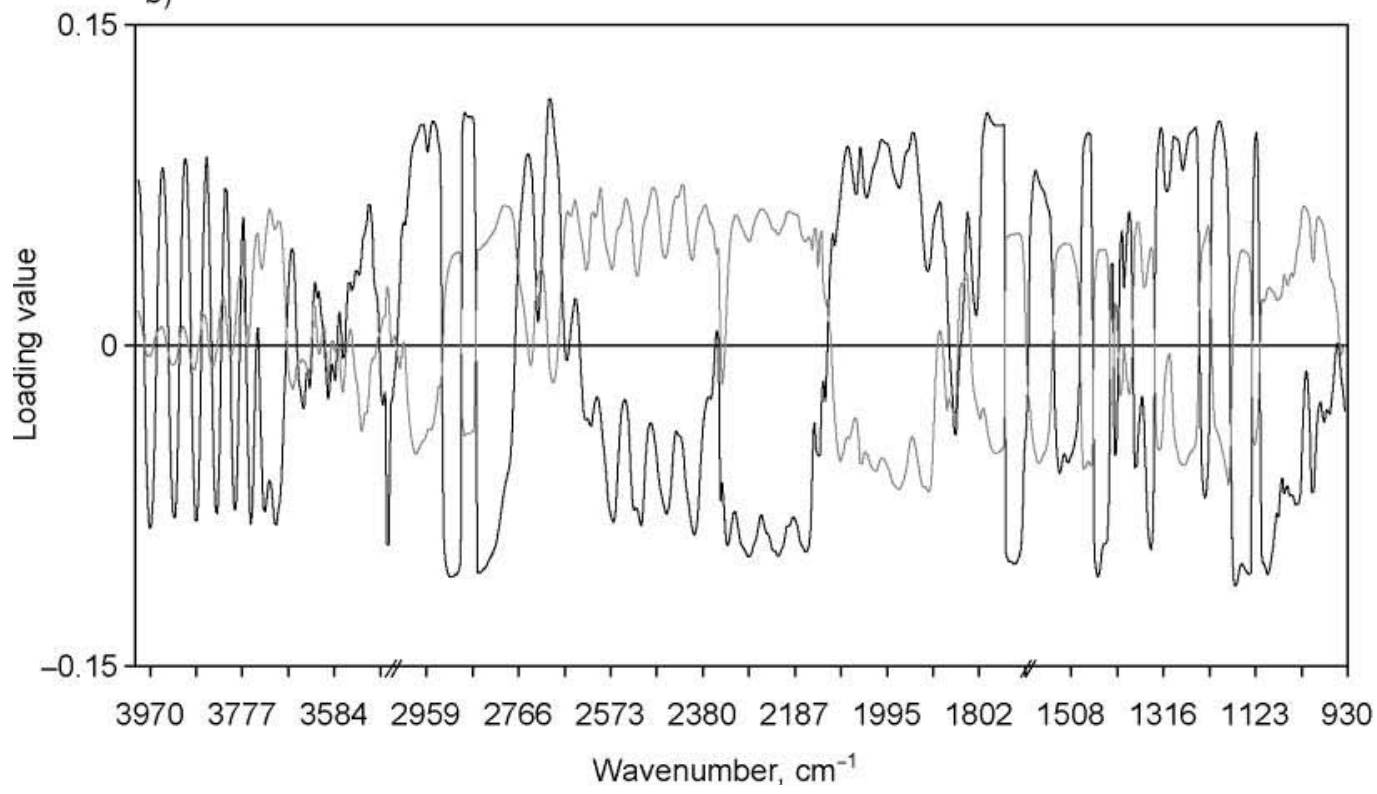

Figure 6. Plot of loadings $1(-)$ and $2(\cdots)$ for a) titratable acidity $\left(\mathrm{SH}^{\circ} / 50 \mathrm{~mL}\right)$ and b) $\mathrm{pH}$ using first derivative mid-infrared spectra. $\mathrm{SH}^{\circ}$ = Soxhlet-Henkel degree.

RCT but significantly influenced curd firming. Indeed, Castillo et al. (2003) stated that increasing the protein content of milk decreased the curd firming time, whereas Dalgleish (1980) found that increasing the casein concentration by ultrafiltration resulted in a firmer final curd. These results highlight the importance of the protein and lipid regions of the mid-infrared spectra in predicting RCT of milk samples.

\section{Prediction of TA and $\mathrm{pH}$}

Table 2 shows that the application of a first-derivative pretreatment resulted in an improvement in model accuracy for TA and $\mathrm{pH}$. In general, N and MSC pretreatments offered no improvement in model accuracy for the analyzed traits, because they resulted in increased RMSECV or \#L values (Table 2). 
The preferred models for predicting $\mathrm{TA}$ and $\mathrm{pH}$ (shown in bold in Table 2) had RMSECV values of $0.25 \mathrm{SH}^{\circ} / 50 \mathrm{~mL}$ and $0.07 \mathrm{pH}$ units, respectively. The corresponding RER values for these models of 14.3 for TA and 16.4 for $\mathrm{pH}$ indicated that the models had high practical utility. Therefore, these parameters had the potential to be predicted by MIR spectroscopy and multivariate data analysis. Figures $5 \mathrm{a}$ and $5 \mathrm{~b}$ show the preferred models for prediction of TA and $\mathrm{pH}$ (highlighted in bold in Table 2). Figure 5a shows that there is less scatter in the TA plot $(r=0.81)$ than may be observed in the MCP plots (Figure 4). The TA model provided approximate predictions $\left(\mathrm{R}^{2}=0.66\right)$, whereas the $\mathrm{pH}$ model allowed for the discrimination between high and low $\mathrm{pH}$ values $\left(\mathrm{R}^{2}=0.59\right)$. The \#L ranged from 9 to 10 for $\mathrm{TA}$ and $\mathrm{pH}$ models, respectively.

The first 2 loadings from the TA model accounted for $55 \%$ of the variation in the spectral data and $36 \%$ of the variation in the TA data. Comparatively, the first 2 loadings from the $\mathrm{pH}$ model accounted for $53 \%$ of the variation in the spectral data and $26 \%$ of the variation in the $\mathrm{pH}$ data. Plots of the first 2 loadings from the $\mathrm{TA}$ and $\mathrm{pH}$ models are shown in Figures $6 \mathrm{a}$ and $6 \mathrm{~b}$, respectively. Considerable structure may be observed in both loading plots. However, it is difficult to assign functional groups to individual peaks. Although the $\mathrm{pH}$ of Emmental cheese has been predicted using MIR spectroscopy $\left(\mathrm{R}^{2}=0.84\right.$; Karoui et al., 2006), no references are available in the literature concerning the utilization of MIR spectroscopy for the prediction of milk TA or $\mathrm{pH}$.

\section{CONCLUSIONS}

The potential of MIR spectroscopy in conjunction with PLS regression to predict milk coagulation properties and milk acidity was demonstrated using 1,064 individual Brown Swiss milk samples. The predictive models developed for RCT and $\mathrm{pH}$ could discriminate between high and low values $\left(\mathrm{R}^{2}=0.59\right.$ to 0.62$)$, whereas the model for the prediction of TA provided an approximate prediction $\left(\mathrm{R}^{2}=0.66\right)$. The $\mathrm{RER}$ value for the $\mathrm{RCT}, \mathrm{TA}$, and $\mathrm{pH}$ predictive models indicated they had high utility values (10.6 to 14.3 ), whereas the prediction model for $\mathrm{a}_{30}$ did not yield useful results. These results suggest that, with further development, MIR spectroscopy has the potential to provide nondestructive and instantaneous measurements of selected milk coagulation and milk acidity properties. As these properties are directly linked to cheese making efficiency, this technique may assist milk processors in optimizing cheese yield. Furthermore, the results obtained suggest the possibility of employing MIR spectroscopy in largescale milk sampling programs focusing on the genetic selection of dairy cattle to improve MCP, where direct analysis is not feasible because of the cost and timeconsuming laboratory measurements required.

\section{ACKNOWLEDGMENT}

The authors acknowledge financial support from PRIN2005-prot. 2005074889_002, of the Italian Ministry of University and Research (MIUR) and Veneto Agricoltura laboratory of Thiene (Italy) for milk analyses.

\section{REFERENCES}

Al-Qadiri, H. M., M. Lin, M. Al-Holy, A. G. Cavinato, and B. A. Rasco. 2008. Monitoring quality loss of pasteurized skim milk using visible and short wavelength near infrared (SW-NIR) spectroscopy $(600-1100 \mathrm{~nm})$ and multivariate analysis. J. Dairy Sci. 91:950958.

Anonymous. 1963. Säuregradbestimmung nach Soxhlet-Henkel (SH). Titratable acidity evaluation with the Soxhlet-Henkel (SH) method. Milchwissenschaft 18:520.

Bastian, E. D., R. J. Brown, and C. A. Ernstrom. 1991. Plasmin activity and milk coagulation. J. Dairy Sci. 74:3677-3685.

Bittante, G., M. Marusi, F. Cesarini, M. Povinelli, and M. Cassandro. 2002. Genetic analysis on milk rennet-coagulation ability in Italian Holstein cows. Proceedings of the 7th World Congress on Genetics Applied to Livestock Production, Montpellier, France. Commun. No. 09-03.

Cassandro, M., A. Comin, M. Ojala, R. Dal Zotto, M. De Marchi, L. Gallo, P. Carnier, and G. Bittante. 2008. Genetic parameters of milk coagulation properties and their relationships with milk yield and quality traits in Italian Holstein cows. J. Dairy Sci. 91:371-376.

Castillo, M., F. A. Payne, C. L. Hicks, J. Laencina, and M. B. Lopez. 2003. Effect of protein and temperature on cutting time prediction in goats' milk using an optical reflectance sensor. J. Dairy Res. 70:205-215.

Coates, J. 2000. Interpretation of infrared spectra, a practical approach. Pages 10815-10837 in Encyclopedia of Analytical Chemistry. R. A. Meyers, ed. John Wiley \& Sons, New York, NY.

Curley, D. M., T. F. Kumosinski, J. J. Unruh, and H. M. Farrell Jr. 1998. Changes in the secondary structure of bovine casein by Fourier transform infrared spectroscopy: Effects of calcium and temperature. J. Dairy Sci. 81:3154-3162.

Dalgleish, D. G. 1980. Effect of milk concentration on the rennet coagulation time. J. Dairy Res. 47:231-235.

De Marchi, M., G. Bittante, R. Dal Zotto, C. Dalvit, and M. Cassandro. 2008. Effect of Holstein-Friesian and Brown Swiss breeds on quality of milk and cheese. J. Dairy Sci. 91:4092-4102.

De Marchi, M., R. Dal Zotto, M. Cassandro, and G. Bittante. 2007. Milk coagulation ability of five dairy cattle breeds. J. Dairy Sci. 90:3986-3992.

Downey, G., E. Sheehan, C. Delahunty, D. O'Callaghan, T. Guinee, and V. Howard. 2005. Prediction of maturity and sensory attributes of Cheddar cheese using near infrared spectroscopy. Int. Dairy J. 15:701-709.

Etzion, Y., R. Linker, U. Cogan, and I. Shmulevich. 2004. Determination of protein concentration in raw milk by mid-infrared Fourier transform infrared/attenuated total reflectance spectroscopy. J. Dairy Sci. 87:2779-2788.

Fagan, C. C., C. Everard, C. P. O'Donnell, G. Downey, E. M. Sheehan, C. M. Delahunty, and D. J. O'Callaghan. 2007. Evaluating midinfrared spectroscopy as a new technique for predicting sensory texture attributes of processed cheese. J. Dairy Sci. 90:11221132 . 
Formaggioni, P., M. Malacarne, A. Summer, E. Fossa, and P. Mariani 2001. Milk with abnormal acidity. The role of phosphorus content and the rennet-coagulation properties of Italian Friesian herd milks. http://www.unipr.it/arpa/facvet/annali/2001/formaggioni. pdf. Accessed January 2008.

Hewavitharana, A. K., and B. V. Brakel. 1997. Fourier transform infrared spectrometric method for rapid determination of casein in raw milk. Analyst (Lond.) 122:701-704.

Hubert, M., and K. Vanden Branden. 2003. Robust methods for partial least squares regression. J. Chemometr. 17:537-549.

Ikonen, T. 2000. Possibilities of genetic improvement of milk coagulation properties of dairy cows. PhD Diss. Univ. Helsinki, Finland. http:// ethesis.helsinki.fi/julkaisut/ maa/kotie/vk/ikonen.

Ikonen, T., K. Ahlfors, R. Kempe, M. Ojala, and O. Ruottinen. 1999. Genetic parameters for the milk coagulation properties and prevalence of noncoagulating milk in Finnish dairy cows. J. Dairy Sci. 82:205-214.

Ikonen, T., A. Morri, A. M. Tyrisevä, O. Ruottinen, and M Ojala. 2004. Genetic and phenotypic correlations between milk coagulation properties, milk production traits, somatic cell count, casein content and pH of milk. J. Dairy Sci. 87:458-467.

Jørgensen, K., and T. Næs. 2004. A design and analysis strategy for situations with uncontrolled raw material variation. J. Chem. (Kyoto) 18:45-52.

Karoui, R., A. M. Mouazen, É. Dufour, L. Pillonel, E. Schaller, D. Picque, J. de Baerdemaeker, and J. O. Bosset. 2006. A comparison and joint use of NIR and MIR spectroscopic methods for the determination of some parameters in European Emmental cheese. Eur. Food Res. Technol. 223:44-50.

Lefèvre, T., and M. Subirade. 2000. Interaction of $\beta$-lactoglobulin with phospholipids bilayers: A molecular level elucidation as revealed by infrared spectroscopy. Int. J. Biol. Macromol. 28:59-67.

Luginbühl, W. 2002. Evaluation of designed calibration samples for casein calibration in Fourier transform infrared analysis of milk. Lebensm. Wiss. Technol. 35:554-558.
Lynch, J. M., D. M. Barbano, M. Schweisthal, and J. R. Fleming 2006. 368 Precalibration evaluation procedures for mid-infrared milk analyzers. J. Dairy Sci. 89:2761-2774.

Mariani, P., P. Serventi, and E. Fossa. 1997. Contenuto di caseina, varianti genetiche ed attitudine tecnologico casearia del latte delle vacche di razza Bruna nella produzione del formaggio grana. Allegato a La Razza Bruna Italiana. 2:8-14.

Martens, H., and T. Naes. 1989. Models for calibration. Chapter 3 in Multivariate Calibration. H. Martens and T. Naes, ed. John Wiley \& Sons Ltd., London, UK.

O'Callaghan, D. J., E. P. Mulholland, A. P. Duffy, C. P. O'Donnell, and F. A. Payne. 2001. Evaluation of hot wire and optical sensors for on-line monitoring of curd firmness during milk coagulation. Ir. J. Agric. Food Res. 40:227-238.

O'Callaghan, D. J., C. P. O'Donnell, and F. A. Payne. 2000. On-line sensing techniques for coagulum setting in renneted milks. J. Food Eng. 43:155-165.

O'Callaghan, D. J., C. P. O'Donnell, and F. A. Payne. 2002. Review of systems for monitoring curd setting during cheesemaking. Int. J. Dairy Technol. 55:65-74.

Pillonel, L., W. Luginbühl, D. Picque, E. Schaller, R. Tabacchi, and J. O. Bosset. 2003. Analytical methods for the determination of the geographic origin of Emmental cheese: Mid- and near-infrared spectroscopy. Eur. Food Res. Technol. 216:174-178.

Williams, P. 2003. Near-infrared technology getting the best out of light. Page 109 in A Short Course in the Practical Implementation of Near Infrared Spectroscopy for the User. 1.1 ed. PDKProjects Inc., Nanaimo, Canada.

Williams, P. C. 1987. Implementation of near-infrared technology Pages 143-167 in Near-Infrared Technology in the Agricultural and Food Industries. 2nd ed. P. C. Williams and K. Norris, ed. American Association of Cereal Chemists, St. Paul, MN.

Zannoni, M., and S. Annibaldi. 1981. Standardization of the renneting ability of milk by formagraph. Sci. Tecn. Latt. Cas. 32:79-94. 